\title{
A case of recurrent salmonella septicaemia in an infant
}

\author{
*P. J. MITCHELL-JONES \\ B.Sc., F.I.M.L.S.
}

\author{
R. J. SANKEY \\ M.B., Ch.B., M.R.C.P.
}

Royal Liverpool Children's Hospital, Myrtle Street, Liverpool L7 7DG

\begin{abstract}
Summary
A 6-month-old girl was admitted with a febrile illness. Salmonella eastbourne was isolated from the stool and blood cultures. Septicaemia was treated with antibiotics but recurred twice on cessation of therapy. The only focus of infection found was the gut itself. Septicaemia did not recur following loss of the pathogen from the gut.
\end{abstract}

KEY WORDS: salmonellosis, septicaemia, IgA deficiency.

\section{Introduction}

Salmonella septicaemia occurs in about $1.1 \%$ of reported cases of salmonellosis (Hyams et al., 1980; Cherubin et al., 1974). In the U.K. in 1980 one-third of those reported occurred in children under 14 years of age and $71 \%$ of these occurred in infants under 1 year of age giving a much higher incidence in this age group (PHLS, 1980). This report describes a case of salmonella septicaemia in an infant, recurrent in spite of antibiotic therapy, and highlights the possible sequelae of infectious diarrhoea in infants, some difficulties of treatment, and the particular importance of adequate bacteriological investigation especially blood cultures.

\section{Case report}

A female Sudanese infant, aged 6 months, was admitted with a 2-day history of fever, nasal discharge, cough and diarrhoea. She had arrived in this country from the Sudan 8 days earlier. The parents gave a history of unconfirmed dysentry, 'malaria' and 'giardiasis'.

On examination the child was febrile $\left(41^{\circ} \mathrm{C}\right)$ and moderately dehydrated. There was hepatosplenomegaly. Initial investigations revealed a haemoglobin of $10.4 \mathrm{~g} / \mathrm{dl}$, white cell count of $12.6 \times 10^{9} / 1$ with $37 \%$ band forms. Sickledex was negative and blood urea was $22.3 \mathrm{mmol} / \mathrm{l}$. Malaria parasites were not seen in

\footnotetext{
*Present address: Arrowe Park Hospital, Microbiology Department, Upton, Wirral, Merseyside.
}

thick blood films. Faeces contained a large amount of pus cells but no parasites. Urine and cerebro-spinad fluid analyses were normal.

After admission profuse diarrhoea developed an the patient was treated with intravenous fluids Following an initial improvement there was rapio deterioration with increased diarrhoea, pyrexia ang convulsions. In order to control the fits, high dose phenobarbitone, curare and intermittent positive pressure ventilation were required.

Salmonella sp. was isolated on faecal culture an treatment with gentamicin and chloramphenicol gass begun. This organism was isolated from fur ine blood cultures and stool specimens. It was sensitive to gentamicin, cefuroxime, chloramphenicol and côtro moxazole, and was identified as Salmonella eas bourne. Antibiotic therapy was changed to chloram phenicol $(100 \mathrm{mg} / \mathrm{kg})$ alone. Recovery was uneven ful. After 12 days' treatment and negative bloo@ cultures, therapy was stopped although Salmonell $\overrightarrow{\widehat{E}}$ eastbourne was still being excreted in the faeces? Faecal specimens from the family proved negative.

After $36 \mathrm{hr}$ the patient again became clinicalli. septicaemic. Salmonella eastbourne was isolated from blood cultures with unchanged sensitivity. Treatment. was commenced with intravenous cefuroxime $10 \mathrm{~S}$ $\mathrm{mg} / \mathrm{kg}$ for 9 days and then reduced to $30 \mathrm{mg} / \mathrm{kg}$ intramuscularly for a further 12 days. Treatment was discontinued after repeatedly negative blood cultures although the organism persisted in the faeces. Aftex $36 \mathrm{hr}$ septicaemia once again became apparent Salmonella eastbourne was isolated once more frorin. blood culture and treatment with cefuroxime 108 $\mathrm{mg} / \mathrm{kg}$ was re-started.

After the third episode of septicaemia the dosage of cefuroxime was increased to $150 \mathrm{mg} / \mathrm{kg}$. Seven days later Salmonella eastbourne ceased to be isolate from the faeces. Therapy was changed after 10 daye to cotrimoxazole orally $80 \mathrm{mg} / \mathrm{b} . d$., and continue for 3 months. Since then the patient has remained well.

Following the first relapse a variety of investiga 
tions were undertaken to determine a reason for the failure of therapy.

A covert focus of infection was sought by abdominal ultrasonography, radionucleotide imaging of bone and brain, and culture of bile, marrow and liver. Pyelography revealed renal medullary tubular ectasia. There was good renal function and no renal or urinary infection was found.

Investigation of immunoglobulin and complement levels and lymphocyte numbers and function tests showed a low level of immunoglobulin $A$ on two testings: the levels being 0.18 and $0.12 \mathrm{~g} / 1$ with a normal range of $0.5-4.0 \mathrm{~g} / \mathrm{l}$ and a mean of $0.6 \mathrm{~g} / \mathrm{l}$ for this age group. These measurements were obtained by radioimmunoassay techniques.

Minimum inhibitory concentrations (MIC) were found to be ampicillin $2.0 \mathrm{mg} / \mathrm{l}$; gentamicin $0.5 \mathrm{mg} / \mathrm{l}$; chloramphenicol $4.0 \mathrm{mg} / \mathrm{l}$; cefuroxime $4.0 \mathrm{mg} / \mathrm{l}$; cotrimoxazole $0.5 / 9.5 \mathrm{mg} / 1$ and with the exception of chloramphenicol all are below normally attainable serum levels. This may explain the first recurrence. However, the second occurred in spite of adequate levels of a further apparently appropriate antibiotic. The patients' serum level $3 \mathrm{hr}$ after dosage was 8 $\mathrm{mg} / \mathrm{l}$ whilst on $100 \mathrm{mg} / \mathrm{kg}$ cefuroxime.

\section{Discussion}

Salmonella eastbourne is an uncommon isolate in the U.K. Only 13 isolates were reported in 1980. This case is the only report with septicaemia in the U.K. in 1980. No source was found in the family and no other cases were reported concurrently in the same area. It seems probable that this infection was acquired in the Sudan.

The high incidence of salmonella septicaemia in infants may be due to the low levels of $\operatorname{IgA}$ as the serum level at 6 months of age are only a quarter of the normal adult value (Tomasi, 1976). Studies with gnotobiotic animals have shown that the normal microbial flora is the major stimulus for the production of intraluminal IgA (Crabbe et al., 1968). These observations may explain the high incidence of salmonella septicaemia in infants and has led to suggestions that antibiotic therapy should be considered for infants of less than 3 months in the hope of keeping the organism confined to the gastrointestinal tract until the protective immune response of secretory IgA develops due to stimulation by the pathogen (Davis, 1981). However, relapse following cessation of therapy may occur (Nelson, 1981).

In the present case several factors may have predisposed to the recurrence of the septicaemia. The IgA levels were low even after correction for age. IgA deficiency occurs in 1/522 of the population (Holt, Tandy and Anstee, 1977), but is usually asymptomatic unless there is a concomitant $\mathrm{T}$ cell dysfunction.
Although this patient has definite IgA deficiency this alone is unlikely to explain repeated septicaemia in the presence of normal lymphocyte function.

The finding of renal medullary tubular ectasia, often associated with hepatic fibrosis (Kerr et al., 1961), present in this case gave two likely foci for infection but in spite of a careful search no infection was found.

Cefuroxime has previously been used successfully in the treatment of salmonella septicaemia, but it has been shown to have low cellular association (Percival et al., 1981), and there is a possibility of organisms remaining viable intracellularly which could lead to reinfection on cessation of therapy. This observation suggests limitations to in vitro sensitivity testing. Antibiotics with low cellular penetration may fail to eliminate sensitive organisms in spite of serum levels in excess of the MIC.

It is difficult to make clear recommendations for antibiotic therapy because of the high incidence of plasmid mediated resistance amongst Enterobacteriacae (Gill and Hook, 1966; Barros et al., 1977; Bissett, Abbot and Wood, 1974).

Although initial therapy must often be blind, it should take account of known possible resistance. Final choice of antibiotic can only be made after careful appraisal of laboratory findings.

The incidence of salmonella septicaemia in infants and its associated mortality has been well documented (Hyams et al., 1980; Cherubin et al., 1974; Davis, 1981), and although this case is unusual it demonstrates the general principle that the illness may be dangerous and prolonged and therapeutic response unpredictable even with full bacteriological information.

Extreme difficulties may be encountered if the likelihood of septicaemia is overlooked and therapy postponed or blind therapy begun before appropriate investigation. We recommend early and repeated blood cultures in any febrile infant with infective diarrhoea.

\section{Acknowledgment}

We would like to thank Professor F. Harris, Dr R. E. Rewell and Dr Poskitt for permission to describe this case and for their help in preparing the manuscript.

\section{References}

Barros, F., Korzeniowski, O., SAnde, M., Martins, K., Santos, L. \& ROCHA, H. (1977) In vitro antibiotic sensitivity of Salmonellae. Antimicrobial agents and Chemotherapy, 6, 1071.

Bisset, M.L., Aвbot, S.L. \& Wood, R.M. (1974) Antimicrobial resistance and $\mathbf{R}$ factors in salmonella isolated in California. Antimicrobial agents and Chemotherapy, 5, 161.

Cherubin, C.E., Neu, H.C., Imperato, P.J., Harvey, R.P. \& BELLEN, N. (1974) Septicaemia with non-typhoid salmonella. Medicine, 53, 365. 
Crabbe, P.A., Bazin, H., Eyssen, H. \& Heremans, J.F. (1968) The normal microbial flora as a major stimulus for the proliferation of plasma cells synthesising IgA in the gut. International Archives of Allergy, 34, 52.

DAVIS, F.R. (1981) Salmonella sepsis in infancy. American Journal of Diseases in Childhood, 135, 1096.

GILL, F.A. \& HoOK, E.W. (1966) Salmonella strains with transferable antimicrobial resistance. Journal of the American Medical Association, 198, 1267.

Holt, P.D.J., TANDY, N.P. \& ANSTEE, D.J. (1977) Screening of blood donors for IgA deficiency; a study of the donor population of south west England. Journal of Clinical Pathology, 30, 1007.

Hyams, J.S., Durbin, W.A., GRAND, R.J. \& Goldman, D.A. (1980) Salmonella bacteraemia in the first year of life. Journal of Pediatrics, 96, 57.
Kerr, D.N.S., Harrison, C.V., Sherlock, S., Milnes-Walke R. (1961) Congenital hepatic fibrosis. Quarterly Journal (1) Medicine, 177, 91 .

NELSON, J.D. (1981) Antibiotic therapy for salmonella syndromes. American Journal of Disease in Childhood, 135, 1093.

Percival, A., Thomas, E., Hart, C.A. \& Karayiannis, P. (1989 In-vitro activity of Monbactam S.Q.26., 776 against gram-negative bacteria. Journal of Antimicrobial Chemotherapy, 8, 49.

Public Health Laboratory Service (1980) Communicable D ease Surveillance Centre, London. Unpublished.

TOMASI, T.B. (1976) The immune-system of secretions. Foundations of Immunology series, ch. 5. Prentice-Hall, New Jersey.

(Accepted 7 July 1983)
ڤ

$\overrightarrow{0}$

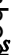

